\title{
Local anaesthetics in the management of duodenal ulceration: A clinical trial of oxethazaine hydrochloride (Mucaine)
}

\author{
ANTHONY H. GRABHAM \\ From the Royal Victoria Infirmary, Newcastle upon Tyne
}

SYNOPSIS A double-blind clinical trial of a potent local anaesthetic used in the treatment of duodenal ulceration is described. No significant difference could be observed in the relief of epigastric pain, back pain or vomiting. The symptom of heartburn was, however, relieved in five out of six cases by the local anaesthetic.

The use of local anaesthetics in the management of dyspepsia has been widely reported, and the results appear to have been very encouraging. During this trial a similar degree of improvement was generally observed. The same degree of improvement, however, was observed when a control antacid preparation was administered.

Local anaesthetics are thought to act partly by a reduction in gastric acidity (Woodward and Schapiro, 1958) and partly by a possible direct action on nerve endings in the gastric and duodenal mucosa. Bayer in 1934 used doses of $100 \mathrm{ml}$. of an $0.25 \%$ solution of an aminobenzoate in the treatment of peptic ulcers, and since then several similar local anaesthetics have been used (Bayer, 1934; Hámori, 1943; Szenes, 1943; Gambigliani-Zoccoli and Zambelli, 1946; Boncour, 1946; Thomas and Kamath, 1950; Balfour and Wharton, 1952).

The efficacy of a local anaesthetic depends partly upon its degree of ionization, for it acts on the nerve endings in its un-ionized form. The effect of gastric acidity, however, is to produce a marked degree of ionization of most local anaesthetics, including those used in previous régimes (Glassman, Hudyma, and Seifter, 1957). Recently, however, a new local anaesthetic agent, oxethazaine, has been developed, which is chemically a glycine amide rather than the usual benzoate or aminobenzoate. It is markedly resistant to ionization in an acid medium (Schwartz and Spertus, 1962). Clinical trials of oxethazaine in the management of oesophagitis (Jankelson and Jankelson, 1959; Ryall, 1962; Sklaroff and Karayannis, 1962), peptic ulceration (Moffitt, 1961 ; Hollander, 1960), and gastritis (Moffitt, 1961; Deutsch and Christian, 1959) seem to have been generally encouraging. A combination of the oxethazaine hydrochloride in aluminium and magnesium hydroxide gel is used, and this preparation (marketed as Mucaine) forms the basis of the present trial.

\section{MATERIAL}

Thirty patients (24 males and six females) with radiologically proven duodenal ulcers formed the subjects for the trial. All had previously received full courses of medical treatment. They were selected, in particular, for the persistence and severity of their symptoms.

\section{METHOD}

All the patients were assessed at the beginning of the trial, and the degree of severity of their major symptoms (epigastric pain, vomiting, heartburn, etc.) was graded. They were then given a course either of the oxethazaine preparation or of a control antacid preparation from which the anaesthetic had been omitted. A dose of two teaspoons was taken before each meal and at bed-time.

After two months the patients were reviewed and reassessed. Those who had been receiving the anaesthetic preparation were then given a supply of the control, and vice versa. Two months later a further review and grading of symptoms was carried out.

Throughout the trial the distribution of either preparation was carried out at random by the dispensary, both the patients and the observer remaining 'blind' until the final grading of symptoms had been made.

\section{RESULTS}

In general, considerable improvement in all symptoms was observed during the trial period. The typical ulcer pain, which had been present persistently in every case, was markedly relieved in all but five. Of the 30 subjects, 25 considered themselves 
generally improved, three were unchanged, and two deteriorated. There was, however, no significant observed difference in the relief of epigastric pain, back pain, or vomiting during the two test periods. That is, the anaesthetic preparation did not seem to produce any improvement which was not produced by the control antacid preparation alone.

The symptom of heartburn had been present in six cases. Of these, five showed a definite improvement while taking the anaesthetic, which was not observed while taking the control preparation.

The patients' overall impression, when asked to express a preference for either preparation, showed no significant difference, six preferring the anaesthetic preparation, eight preferring the control, and the remaining 16 finding 'no difference'.

Throughout the trial, there was no obvious evidence of toxicity, but on direct questioning several patients admitted to either a dry tongue or to some constipation.

\section{DISCUSSION}

Previous observations on the relief of dyspepsia by local anaesthetic compounds have been confirmed. Similar relief, however, has been obtained from a control antacid preparation. This suggests that the anaesthetic itself does not ease the dyspeptic symptoms. As the patients had already failed to respond to medical treatment, using antacids similar to the control, one must look further than the drug for an explanation of the apparently good results. Perhaps the explanation lies in the special interest and care which trial patients inevitably receive.

The observation of relief of heartburn by the anaesthetic preparation supports the observations of previous authors and appears to warrant a full clinical trial in cases of oesophagitis.
I am indebted to Mr. W. P. T. Watts for his advice and for permission to study cases under his care; to Mr. H. Poole, chief pharmacist, and to Messrs. John Wyeth $\&$ Brother Ltd., who supplied both the oxethazaine and the control preparations.

\section{REFERENCES}

Balfour, D. C. Jr., and Wharton, G. K. (1952). Use of procaine hydrochloride by mouth for gastrointestinal disorders. Gastroenterology, 22, 257-262.

Bayer, L. (1934). Uber die Wirkung der Anesthesie der Magenschleimhaut auf den Pfortnerkramf und auf das Magengeschwur. Zbl. inn. Med., 55, 577-584.

Boncour, R. (1946). Traitement de la douleur dans les ulcères gastroduodénaux. Presse méd., 54, 314.

Deutsch, E., and Christian, H. J. (1959). Chronic gastritis. Histological criteria for management and medical treatment with a mucosal anesthetic in aluminum hydroxide. J. Amer. med. Ass., 169. 2012-2015.

Gambigliani-Zoccoli, A., and Zambelli, E. (1946). Sulla terapia dell'ulcera gastro-duodenale con novocaina per os (rilievi clinico-radiolcgici). Minerva med., 2, 493-496.

Glassman, J. M., Hudyma, G. M., and Seifter, J. (1957). Comparative potencies of a new series of local anesthetics. J. Pharmacol. exp. Ther., 119, 150.

Hámori, A. (1943). Die perorale Novocainbehandlung des Magenund Duodenalgeschwürs. Z. klin. Med., 142, 406-413.

Hollander, E. (1960). Oxethazaine for control of symptoms in refractory cases of duodenal ulcer and hiatus hernia. Amer. $J$. Gastroent., 34, 613-618.

Jankelson, I. R., and Jankelson, O. M. (1959). Topical anesthetic and antacid in the treatment of peptic esophagitis. Ibid., 32. 636-641.

Moffitt, R. E. (1961). Comprehensive approach to the management of difficult gastroenterological problems. R.I. med. J., 44, 151-154.

Ryall, R. J. (1962). A short term investigation of 'Mucaine' in reflux oesophagitis. Brit. J. clin. Pract., 16, 797-800.

Schwartz, I. R., and Spertus, I. (1962). Scientific Exhibition, Amer. Coll. Gastroent. Convention, Cleveland, Ohio.

Sklaroff, D. M., and Karayannis, N. (1962). Treatment of radiation esophagitis: report of 51 cases. Curr. ther. Res., 4, 356-362.

Szenes, T. (1943). Die perorale Novocainbehandlung des MagenDuodenalgeschwürs im Lichte der röntgenalogischen Beobachtung. Z. klin. Med., 142, 414-421.

Thomas, T., and Kamath, M. V. (1950). Oral novocaine therapy in peptic ulcer. Indian med. Gaz., 85, 16-18.

Woodward, E. R., and Schapiro, H. (1958). Effect of local anesthetics on the isolated antrum of the stomach in dogs. Amer. $J$. Physiol., 192, 479-481. 